\title{
Mesoscale Variation of Mechanisms Contributing to Stability in Rocky Shore Communities
}

\author{
Nelson Valdivia ${ }^{1 *}$, Andrés E. González², Tatiana Manzur², Bernardo R. Broitman²
}

1 Universidad Austral de Chile, Instituto de Ciencias Marinas y Limnológicas, Laboratorio Costero de Recursos Acuáticos Calfuco, Campus Isla Teja, Valdivia, Chile, 2 Centro de Estudios Avanzados en Zonas Aridas (CEAZA), Facultad de Ciencias de Mar, Universidad Católica del Norte, Larrondo 1281, Coquimbo, Chile

\begin{abstract}
Environmental fluctuations can generate asynchronous species' fluctuations and community stability, due to compensatory dynamics of species with different environmental tolerances. We tested this hypothesis in intertidal hard-bottom communities of north-central Chile, where a persistent upwelling centre maintains a mosaic in sea surface temperatures (SST) over 10s of kilometres along the shore. Coastal upwelling implies colder and temporally more stable SST relative to downstream sites. Uni- and multivariate analyses of multiyear timeseries of SST and species abundances showed more asynchronous fluctuations and higher stability in sites characterised by warmer and more variable SST. Nevertheless, these effects were weakened after including data obtained in sites affected by less persistent upwelling centres. Further, dominant species were more stable in sites exposed to high SST variability. The strength of other processes that can influence community stability, chiefly statistical averaging and overyielding, did not vary significantly between SST regimes. Our results provide observational evidence supporting the idea that exogenously driven compensatory dynamics and the stabilising effects of dominant species can determine the stability of ecosystems facing environmental fluctuations.
\end{abstract}

Citation: Valdivia N, González AE, Manzur T, Broitman BR (2013) Mesoscale Variation of Mechanisms Contributing to Stability in Rocky Shore Communities. PLoS ONE 8(1): e54159. doi:10.1371/journal.pone.0054159

Editor: Simon Thrush, National Institute of Water \& Atmospheric Research, New Zealand

Received September 14, 2012; Accepted December 10, 2012; Published January 11, 2013

Copyright: () 2013 Valdivia et al. This is an open-access article distributed under the terms of the Creative Commons Attribution License, which permits unrestricted use, distribution, and reproduction in any medium, provided the original author and source are credited.

Funding: This study was financially supported by the Fondo Nacional de Desarrollo Cientco y Tecnologico (FONDECYT) through grants \# 3100014 (NV), \# 1090488 (BRB), and \# 1120988 (BRB), by the Consejo Nacional de Ciencia y Tecnologico (CONICYT) through Becas Chile doctoral grant \# 21110859 to AEG, and by the Programa de Mejoramiento de la Calidad y la Equidad de la Educacion Superior (MECESUP) through grant \# AUS0805 Fortalecimiento de las Ciencias Ecologicas y Evolutivas en la UACh to N.V. The funders had no role in study design, data collection and analysis, decision to publish, or preparation of the manuscript.

Competing Interests: The authors have declared that no competing interests exist.

*E-mail: nelson.valdivia@uach.cl

\section{Introduction}

Forecasted scenarios of species loss, ecological phase shifts, and global environmental change have fuelled extensive research on community stability $[1,2]$. Today, we recognise that community stability, measured as the temporal change in ecosystem properties like community productivity and abundance, depends on the strength of at least four mechanisms: compensatory dynamics, species dominance, statistical averaging, and overyielding [1,3,4]. Stability varies widely among natural communities [5] and it still is unclear how stabilising mechanisms interplay across different environmental conditions.

The stabilising mechanisms listed above depend on the magnitude and type of temporal variation in species abundances. For example, asynchronous and compensatory dynamics of competing species with differential environmental tolerances can maintain stability, because the decrease of stress-intolerant species can be compensated by growth of others (reviewed in [6]). Recent studies show that dominance may lead to more stable assemblages [7], as the abundance of competitively superior species can be less variable (e.g. resistant to disturbance) than subordinate ones [8]. Dominance, therefore, may increase stability by means of a mechanism analogous to the sampling effect $[7,9]$. In addition, recent theoretical work indicates that unevenness in species abundances influences both, species synchrony and the average population variability [10]. Statistical averaging is another mechanism responsible for community stability. Since variance is a power function of the mean [11], species with large abundances display exponentially larger population variance than species with small abundances. The slope of the mean-variance scaling relationship, $z$, determines the contribution of statistical averaging to stability, with $1<z<2$ meaning that increasing diversity increases and dampens population- and community-level variability, respectively [4,12]. Finally, overyielding enhances stability and takes place when mean community-level properties, such as total abundance, increases with diversity faster than its variance [13]. Statistical averaging and overyielding are not mere artefacts. For example, $z$ values $<2$ and disproportional increases of the temporal mean of an aggregate property can be caused by fundamental ecological mechanisms such as negative species interactions and resource complementarity, respectively $[13,14]$.

Theory and laboratory-based experiments indicate that variations in environmental factors can affect the strength of mechanisms promoting stability, particularly compensatory dynamics (e.g. [15-17]). Large environmental fluctuations in abiotic factors like temperature can generate synchronous fluctuations and reduce stability [18]. However, if different species are competitively superior at different times, following differential environmental tolerances, and if the effects of competition and environmental stress on per capita growth rates are positively correlated, environmental variability can actually lead to asynchronous dynamics in species fluctuations [19-21]. These 
exogenously driven compensatory dynamics (sensu [sensu 6]) can have strong stabilising effects on aggregate ecosystem properties [20].

In coastal ecosystems, variations in oceanographic and atmospheric conditions represent a relevant source of environmental fluctuations for coastal communities. Along mid-latitude, eastern oceanic boundaries, earth's rotation, and prevailing equatorward winds displace coastal surface waters offshore, which are replaced by cold, nutrient-rich water upwelled from the subsurface. The process of coastal upwelling-usually locked to coastal promontories or headlands and where upwelling-favourable winds maintain nearshore waters cold-drives a strong temperature inversion at the ocean-atmosphere interface and maintains a shallow stratus cloud deck associated to onshore coastal topography [22,23]. As a consequence, bays located downwind from upwelling centres show different temporal patterns of variation in sea surface temperature (SST), which are evidenced in the temporal structure of SST variance (e.g. [24]). A growing body of evidence indicates that such persistence in spatially structured variation in oceanographic conditions over 10's to 100 's of $\mathrm{km}$ (i.e. mesoscale) is correlated to spatial variation in species- and community-level properties. In intertidal habitats, the temporal stability in body temperatures of mussels [25] and growth rates of corticated algae [26,27] are positively affected by upwelling activity [28]. Moreover, recruitment of intertidal sessile invertebrates, in addition to positive biotic interactions, seems to be dampened [26,28,29]. Accordingly, the structure of sessile hard-bottom assemblages appears to be significantly correlated to mesoscale regimes of SST variance [24,30]. If temporal variation in environmental conditions affects temporal variation in species abundance, then it can be predicted that temporal SST patterns will be associated to the strength of compensatory dynamics and stability of intertidal communities.

Hereby, we tested the general hypothesis that environmental fluctuations lead to compensatory dynamics and stability in intertidal hard-bottom communities. Our model system was the north-central coast of Chile (ca. $\left.30^{\circ} \mathrm{S}\right)$, where a persistent upwelling centre, extending $\sim 100 \mathrm{~km}$, maintains significant mesoscale differences in climatic and oceanographic conditions [22]. We tested the specific predictions that (1) sites affected by persistent and reduced upwelling activity show different patterns of temporal variation in SST, and (2) these two environmental regimes drive significant differences in species synchrony and community stability of hard-bottom communities. We further tested whether (3) the strength of other stabilising mechanisms, such as species dominance, statistical averaging, and overyielding, covary with the temporal variation in SST.

\section{Materials and Methods}

This study was conducted as part of the activities carried out by the Changolab at the Centro de Estudios Avanzados en Zonas Áridas (CEAZA) and approved by its bioethics committee. In addition, the study conforms to the Art. §7 Law 19.300 "Bases Generales del Medio Ambiente", which supports research on ecology and environmental science. No specific permits were required for the described field studies, because they were based on non-destructive estimations of species abundances and only few specimens (mostly filamentous algae) were collected when in situ identification was unfeasible. These species were not among endangered or protected species and locations were not privatelyowned or protected by law.

\section{Study Sites}

Observations were conducted on the north-central rocky shores of Chile, around a persistent upwelling centre (Fig. 1). Punta Lengua de Vaca, around $30.5^{\circ} \mathrm{S}$ (PLV hereafter), is a $2.4 \mathrm{~km}$ long peninsula, extending towards the equator and abutting the southern end of a large bay system. Sites located south of PLV are characterized by persistent upwelling activity, while sites located inside the bay (i.e. north of PLV) may receive water upwelled at PLV, but they experience little wind-driven coastal upwelling [29]. The study area around PLV corresponds to the transition between two mesoscale regions with contrasting oceanographic conditions: a northern region characterised by low eddy activity driven by weak but sustained upwellingfavourable winds, and a southern region characterised by high eddy activity driven by strong and prolonged episodes of upwelling favourable winds [31-34]. Accordingly, events of relaxation from upwelling are more frequent south than north of PLV [29]. Episodes of sea surface warming after relaxation from upwelling dominate high-frequency variability in SST, particularly during spring [32]. Such warm events can play a key biological role as onshore advection of recently upwelled waters can bring planktonic larvae and high nutrient concentrations to the intertidal community [35] and can lead to phytoplankton blooms nearshore [36].

We selected four sites that differed in their position relative to the PLV upwelling centre (Fig. 1). The southern sites, Limarí and Punta Talca, were located near the core of the upwelling centre; the northern sites, Panul and Guanaqueros, were located inside the large bay abutted by PLV. Southern and northern sites were, therefore, exposed to high and low intensity of upwelling activity, respectively.

The study region is characterised by spatial variation in terms of composition and abundance of species. For example, the dominant corticated red alga Mazzaella laminarioides and the large bull-kelp Durvillaea antarctica find their northern geographic range limit around this zone [37]. In addition, beds of the purple mussel Perumytilus purpuratus, characteristic on the mid intertidal zone of south-central shores, become scarce and are replaced by increased empty space and patches of chthamalid barnacles [29]. Despite these changes, opportunistic algae like Ulva compressa, $U$. rigida, and Pyropia sp. are persistent across the entire study region [37]. In the high and mid-intertidal zones, mobile grazers include several species of scurrinid limpets (Scurria spp.), chitons, and keyhole limpets (e.g. Fissurella crassa). In the low intertidal zone, the kelp Lessonia nigrescens and the bull kelp Durvillaea antarctica form dense canopies and support a diverse assemblage of mobile invertebrates, including chitons like Enoplochiton niger and Chiton granosus, keyhole limpets like Fissurella limbata, and turban snails like Tegula spp. and Prisogaster niger [38-40].

\section{Sampling}

At each site, we selected mid-intertidal rocky platforms with similar slopes, wave-exposure, and orientation to prevailing southwest winds, where we estimated species percentage cover on ten $0.25 \mathrm{~m}^{2}$ plots located along ca. $20 \mathrm{~m}$ alongshore transects. The position of each plot was permanently marked with stainlesssteel bolts and rings. Plots were haphazardly positioned, but positions were restricted to flat and gently sloped surfaces lacking crevices and tide pools. This protocol has been used in several studies on benthic diversity along Chilean coasts and elsewhere (e.g. $[5,37,38,41])$.

Percentage cover of each sessile macro-epibenthic $(>5 \mathrm{~cm})$ species was estimated on each plot every three months between May 2009 and February 2012. Estimations were conducted during 


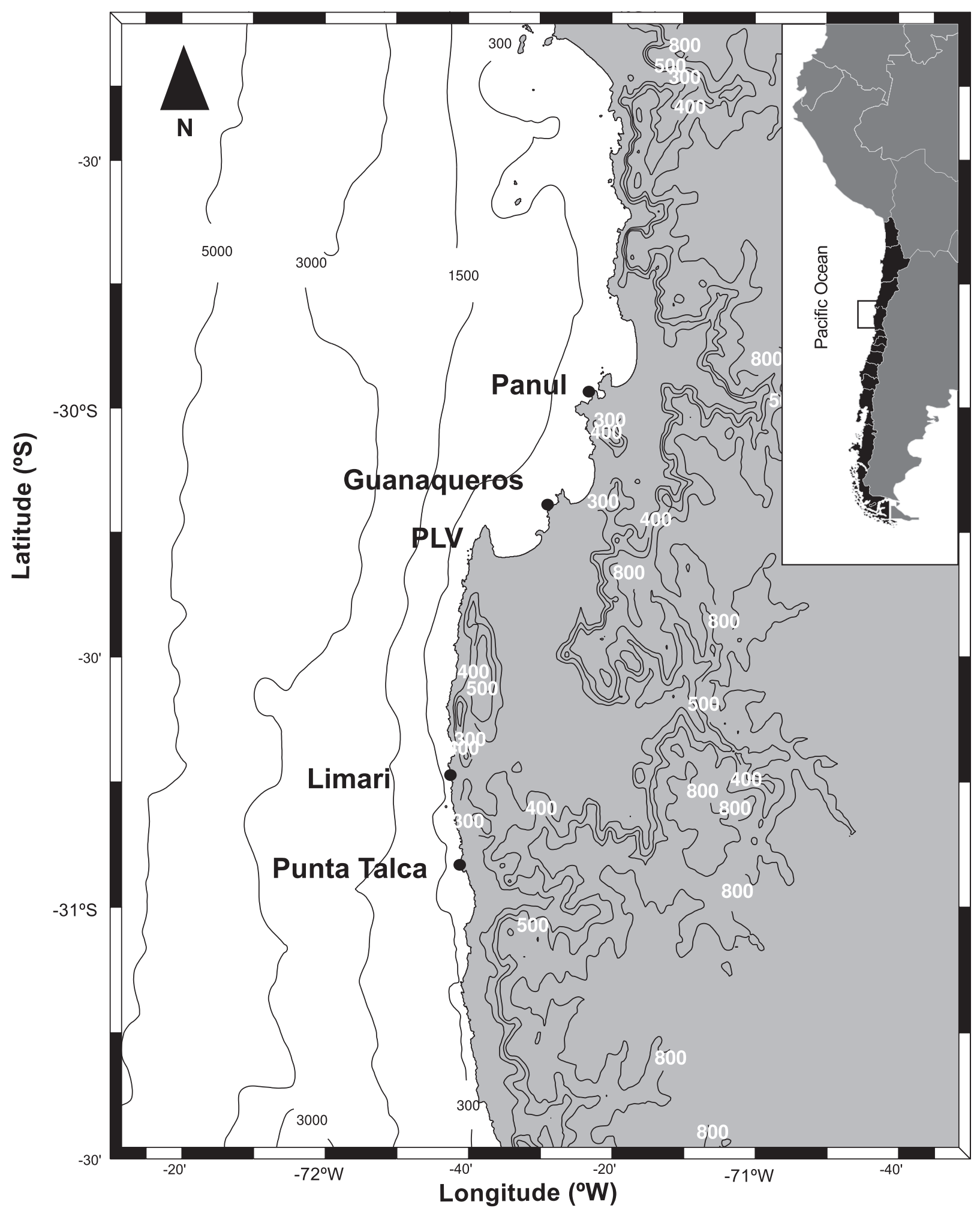

Figure 1. Location of the four sampling sites (Panul, Guanaqueros, Limarí, and Punta Talca) around the persistent upwelling centre located south Punta Lengua de Vaca (PLV). Bathymetric and topographic reliefs are also shown. doi:10.1371/journal.pone.0054159.g001

daytime low-tide intervals and to the nearest $1 \%$ by means of $0.25 \mathrm{~m}^{2}$ quadrats subdivided in 25 equal fields. Percentage cover directly reflects resource availability in hard-bottom communities, where competition for settlement surfaces is a pivotal driver of species dynamics [42]. In addition, percentage cover is routinely used as a proxy for species abundances [43], and can be 
significantly correlated with biomass on these shores [24] and elsewhere $[44,45]$. Accordingly, we assumed that percentage cover was appropriate to assess temporal dynamics in species abundances.

Our study represented a conservative estimate of the biodiversity at each site, because observations were focused on macroepibenthic organisms for which appropriate taxonomic keys were available and therefore were possible to accurately be identified in the field [46-48]. Nevertheless, the resulting subset of species encompassed a diverse taxonomic group that included several phyla and species from at least three trophic levels. Organisms were identified in the field to the lowest possible taxonomic level and few specimens were collected from adjacent areas and identified in the laboratory. We considered that a mixture of taxonomic resolution was appropriate for assessing communitylevel stability, as previous work shows that similar patterns in community structure are apparent whether fine, coarse, or mixed taxonomic resolution is used [49,50]. Further details of sampling procedure in these sites are published elsewhere [37,38].

We used in situ measurements of sea surface temperature (SST) to characterise the environmental variability. Between August 2009 and August 2011, we deployed at each site temperature dataloggers that recorded SST every 10 minutes. Each data-logger was enclosed into a PVC pipe, which was inserted into a concrete block moored at 1-m depth [51].

\section{Statistical Analyses}

The magnitude of environmental fluctuations in each site was estimated using temporal variances calculated from the two-year daily SST measurements where the few missing observations in the time series were interpolated using a cubic spline. Temporal variances were calculated separately from daily to trimonthly temporal scales $(1,5,30$, and 90 days) using a running-mean filter.

In order to illustrate multivariate patterns in community structure across sites, we used canonical analysis on principal coordinates (CAP [52]). CAP is a constrained multivariate method that uses an a priori hypothesis to produce an ordination plot, allowing the detection of patterns that could be masked by overall dispersion in unconstrained methods such as multidimensional scaling. CAP plots were based on a fit between a vector of sites and a matrix of Bray-Curtis dissimilarities calculated from raw percentage cover data. In addition, individual taxa that might have influenced any differences among sites seen in the CAP ordination were investigated by calculating product-moment correlations of species abundances with canonical ordination axes. We included in CAP only taxa having a mean percentage cover $>5 \%$ in order to reduce distortion in the ordination plots. The test for different levels of stability between sites was complemented in a multivariate context by means of a permutation distance-based test for homogeneity in multivariate dispersion (i.e. PERMDISP [53]). The significance of F-statistic from ANOVA of Bray-Curtis distances to group centroids was interpreted by means of 999 permutations of model residuals that generated a distribution of $\mathrm{F}$ under the null hypothesis of no difference in dispersion between sites.

Stability has several meanings in ecology, which include concepts like the magnitude of disturbances a system can tolerate (domain of attraction), the magnitude of changes driven by a disturbance (resistance), how long a the system requires to return to a specified fraction of its initial state (resilience) and how much a measure varies over time (variability) [54-57]. Pioneer studies on ecological stability explicitly considered stability as related to temporal variation in ecosystem properties $[58,59]$. In this work, we used the temporal variability in total community cover as an overall measure of stability. Community stability was expressed as the ratio between the long-term temporal mean and standard deviation $(S=\mu / \sigma)$ of total percentage cover; i.e., the sum of the abundances of all species in the assemblage [13]. Both, $\mu$ and $\sigma$ were formally analysed to address whether mesoscale variation of stability was related to variations of mean abundances or temporal variability.

In order to measure community-wide synchrony in species abundances, we used the $\varphi_{x}$ statistic [60]:

$$
\vartheta_{x}=\sigma_{x_{T}}^{2} /\left(\sum_{i=1}^{N} \sigma_{x_{i}}\right)^{2}
$$

where $\varphi_{x}$ describes the variance in the sum of all species abundances (i.e. total community abundance, $x_{T}$ ) relative to the squared sum of the standard deviations of all $\mathcal{N}$ individual species $\left(x_{i}\right) \cdot \varphi_{x}$ is standardised between 0 (perfect asynchrony) and 1 (perfect synchrony; i.e. most species are positively correlated); and is independent of the magnitude and distribution of species abundances and variances, allowing quantitative comparisons of communities with different species richness. The $\varphi_{x}$ statistic uses the fact that the variance of an aggregate property can be partitioned into the sum of all species variances plus the sum of all pair-wise species covariances [61] such that:

$$
\sigma_{x_{T}}^{2}=\sum_{i=1}^{N} \sigma_{x_{i}}^{2}+2\left(\sum_{i=1}^{N} \sum_{j=1}^{i-1} \sigma_{\left(x_{i}, x_{j}\right)}^{2}\right)
$$

Species dominance was expressed as $D=\sum_{s=1}^{S} p_{s}^{2}$, where $D$ is the Simpson dominance index, $p_{s}=x_{s} / \sum^{x}, x$ is the relative abundance of the sth species, and $S$ is the number of species in the sample. Statistical averaging effects depend on how the temporal variance in the abundance of a species changes with its temporal mean [12]. The scaling of variance $\sigma^{2}$ with the mean $\mu$ is described by Taylor's power function, $\sigma^{2}=c \mu^{z}$, where $c$ is a constant and $z$ is the scaling coefficient [11]. The value of $z$ affects the strength of the statistical averaging, with $1<z<2$ meaning that diversity increases and dampens the population- and community-level variability, respectively [12]. The logarithmic transformation of $\sigma^{2}=c \mu^{z}$ results in a linear equation in the form of $\log \left(\sigma^{2}\right)=c+z \log$ $(\mu)$. We fitted this linear relationship to the entire dataset, combining all species. The $z$-values obtained from each regression were used as dependent variables. In addition, regression residuals for each species were used to estimate species-level stability, and thus infer whether species with larger percentage covers (i.e. dominant species) were more stable; larger negative residuals indicated higher species-level stability [7]. We tested the relationship between species-level stability and dominance by estimating Pearson product-moment correlation coefficients $(r)$ between residuals and the long-term means of species' percentage covers. Significance was tested for each site by testing observed correlation coefficients against a null distribution of $r$ coefficients generated from 10000 randomisations [7]. Overyielding was estimated for each plot as the slope of the regression of total community cover vs. taxon richness [13]. Within each plot, the regression was calculated with the sampling dates as replicates and the effect of temporal autocorrelation was reduced by means of a mixed-effects model and best linear unbiased predictors [5].

We used separate 2-way nested analyses of variance (ANOVAs) with 'region' (2 levels: either north or south PLV) as a fixed factor 


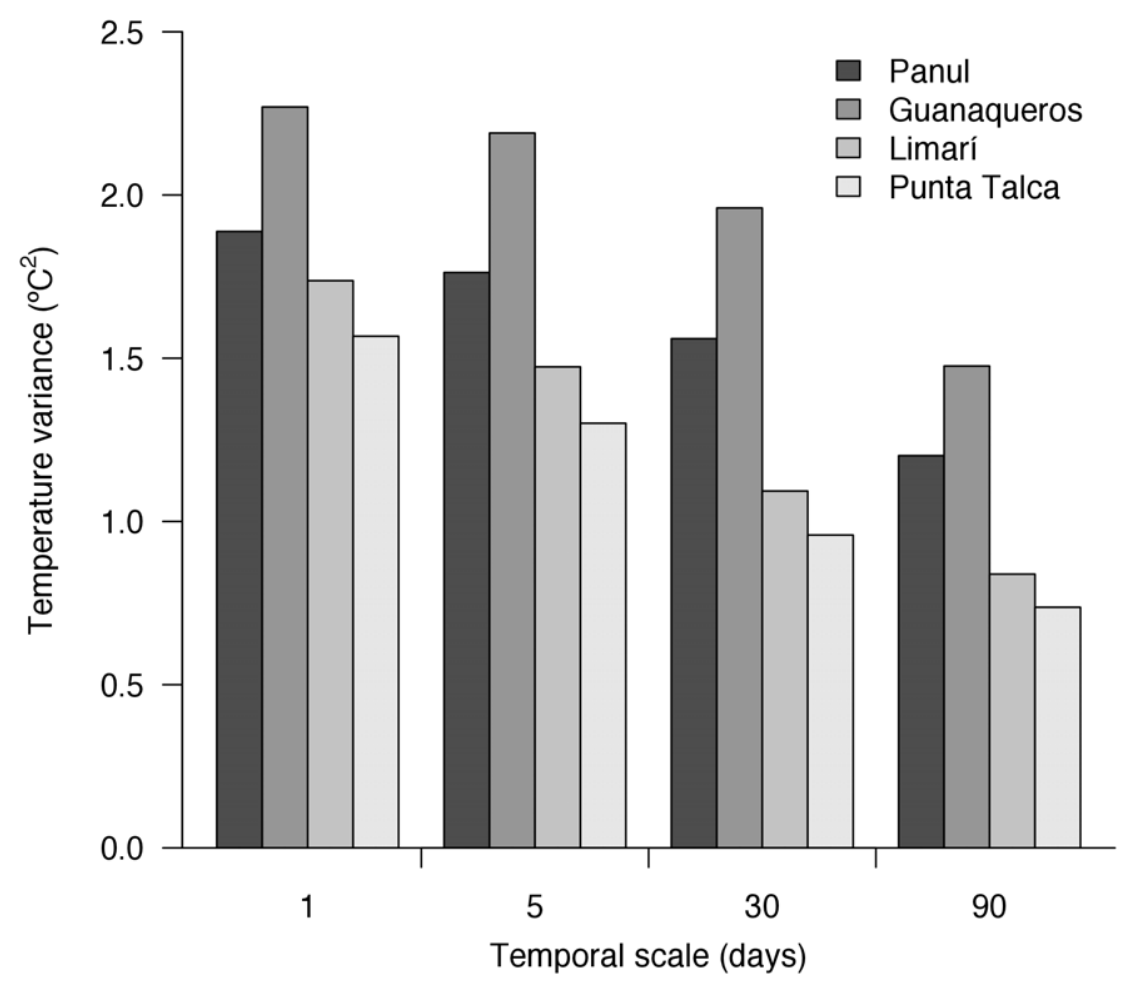

Figure 2. Long-term variance in sea surface temperatures (SST) recorded in sites located north (Panul and Guanaqueros) and south (Limarí and Punta Talca) the upwelling centre at Punta Lengua de Vaca (PLV). SST values were recorded every 10 minutes at 1 metre depth.

doi:10.1371/journal.pone.0054159.g002

and 'site' (2 levels) as a random factor and nested in 'region' to test the prediction that sites with different degrees of temporal variation in SST show significant differences in stability and the stabilising mechanisms. After running the full models, highly conservative $(P \geq 0.25)$ error terms were removed and F-ratio statistics were then recalculated with a pooled denominator [62]. Homogeneity of variance was graphically explored by means of residuals-vs.-fits and normal Q-Q plots. In order to achieve homogeneity of variances, data of $S$ and $\varphi_{x}$ were $\log _{10}$ transformed, and those of $\sigma$ were square root transformed.

In addition to the datasets described above, we analysed a multiyear (1998-2005) dataset of species percentage covers estimated in 17 sites and spanning ca. $733 \mathrm{~km}$ of the coast $\left(29.47^{\circ} \mathrm{S}-36.07^{\circ} \mathrm{S}\right)$. In each of these sites, species percentage covers were estimated on randomly located $0.25 \mathrm{~m}^{2}$ plots on a regular basis. Most sites were sampled every six months from 1998 to 2000 and then from 2003 to 2005 (see Table S1). Each site was categorised either as exposed to warm or cold SST according to Broitman et al. [38], Nielsen and Navarrete [27], and Wieters [26]. For each site, we estimated temporal variance components in total community cover $\left(\sigma^{2}\right)$ by means of restricted maximum likelihood (REML). The regional trend in variance components was removed after calculating the residuals from locally weighted regression scatterplot smoothing (LOWESS) against latitude. The hypothesis that stability (i.e. the inverse of temporal variability in total community cover) differs between sites exposed to warmer and colder SST was tested with a 1-way ANOVA with 'SST' (two levels, cold and warm SST) as fixed factor and the residuals of variance components as dependent variable. SST analyses were conducted in Matlab (v7.8.0, The Mathworks, Natick, Massachusetts, USA). All other estimations and statistical analyses were conducted in R 2.15.0 [63].

\section{Results}

Our observations showed that SST was higher at Panul $\left(\right.$ median $=13.7^{\circ} \mathrm{C}, \quad$ range $\left.=12.4-17.4^{\circ} \mathrm{C}\right)$ and Guanaqueros

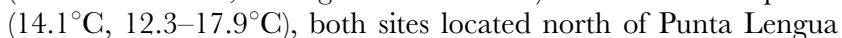
de Vaca (PLV); than at Limarí $\left(12.7^{\circ} \mathrm{C}, 11.3-16.7^{\circ} \mathrm{C}\right)$ and Punta Talca $\left(12.6^{\circ} \mathrm{C}, 11.2-16.5^{\circ} \mathrm{C}\right)$, both located south of PLV. Temporal variances of SST were, on average, $50 \%$ larger at Panul and Guanaqueros that at Limarí and Punta Talca (Fig. 2). The differences between northern and southern sites were stronger when the variances were calculated at the monthly and trimonthly scales, where SST records were ca. 70\% more variable north than south of PLV (Fig. 2). Across scales of variability, the largest and smallest variances were observed at Guanaqueros (2.23) and Punta Talca (0.74), respectively (Fig. 2). These results support the prediction that sites categorised as experiencing low (Panul and Guanaqueros, north of PLV) and high (Limarí and Punta Talca, south of PLV) upwelling activity show different patterns of temporal variation in SST.

According to the observed spatial structure in SST, sites north and south of PLV showed different community structures (Fig. 3). Canonical analyses of principal coordinates (CAP) showed larger multivariate dispersion in Guanaqueros and Panul (northern sites) than in Punta Talca and Limarí (southern sites, Fig. 3a). Permutation analyses of homogeneity of group multivariate dispersion showed significant differences among sites $\left(\right.$ pseudo- $\mathrm{F}_{3}$, $396=60.059, \mathrm{P}=0.001)$. Pairwise comparisons and CAP ordinations (Fig. 3a) indicated that group-specific distances to centroids were Panul $>$ Guanaqueros $>$ Limarí $=$ Punta Talca. Chthamalid barnacles dominated the assemblages north of PLV, while the corticated red alga Mazzaella laminarioides and the crustose Lithothamnion spp. dominated the sites south of PLV (Fig. 3b). 


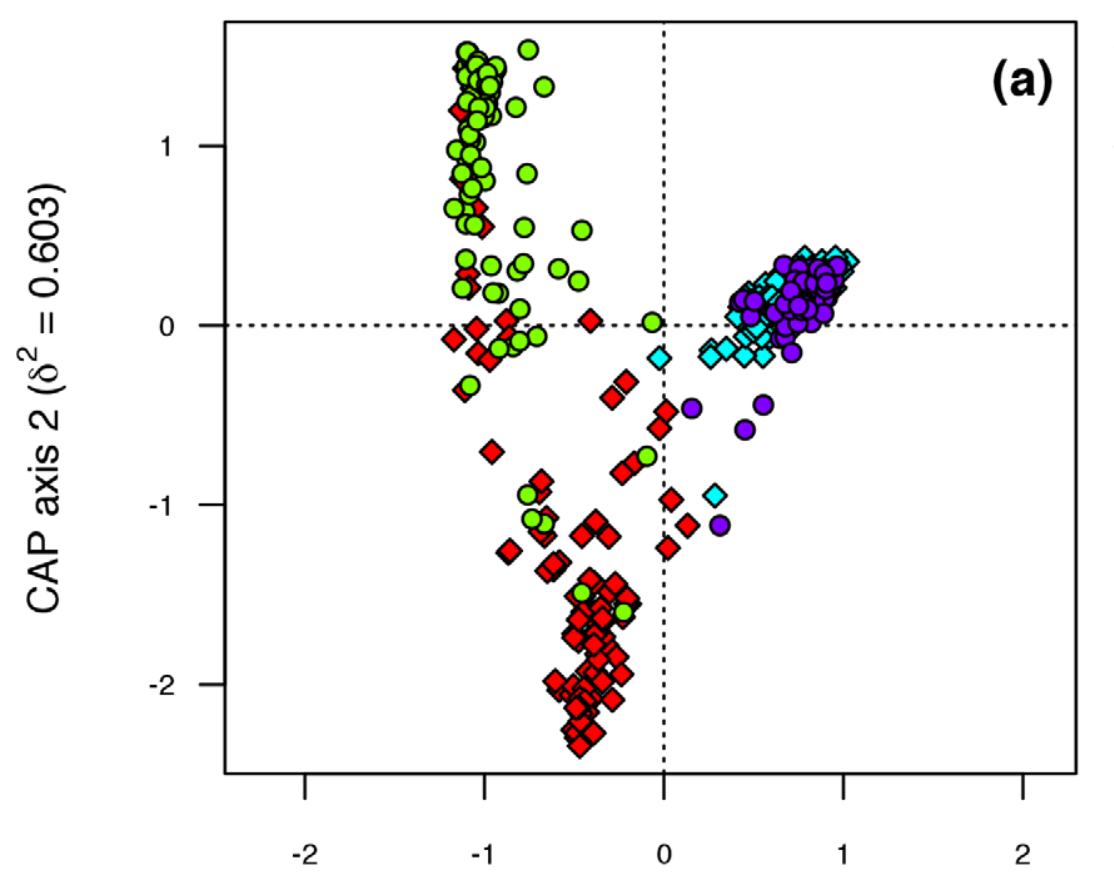
$\diamond$ Panul
- Guanaqueros
$\diamond$ Limarí
- Punta Talca

CAP axis $1\left(\delta^{2}=0.922\right)$

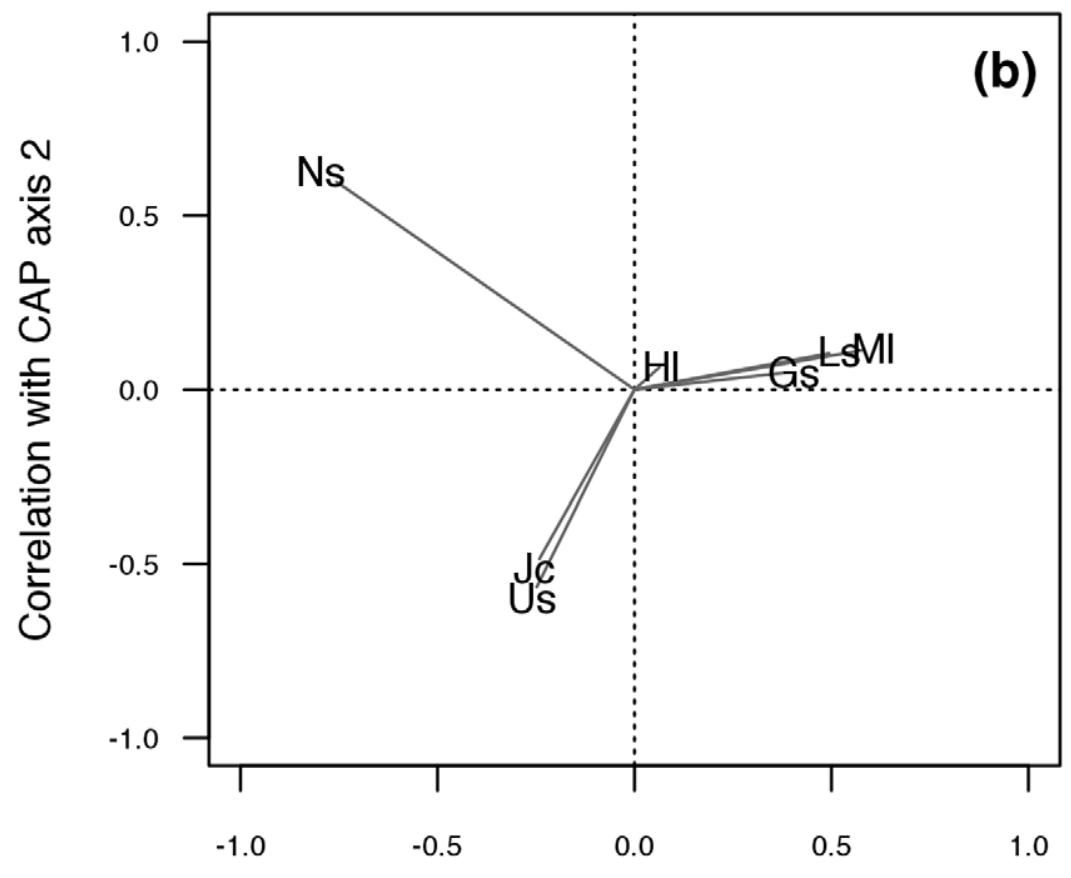

Jc: Jehlius cirratus

Ns: Nothochthamalus scabrosus

Us: Ulva spp.

Gs: Gelidium sp.

Ml: Mazzaella laminarioides

HI: Hildenbrandia lecannellieri

Ls: Lithothamnion spp.

\section{Correlation with CAP axis 1}

Figure 3. Canonical analysis of principal coordinates (CAP) ordination: (a) Canonical axes that best discriminate the assemblages from sites located north (Panul and Guanaqueros) and south (Limarí and Punta Talca) to the upwelling centre at Punta Lengua de Vaca (PLV). (b) Correlations of original taxa with canonical axes. CAP was significant with $P=0.005$. Taxa with average cover $<5 \%$ were excluded from the analysis in order to reduce distortion in the ordination.

doi:10.1371/journal.pone.0054159.g003

Community stability, measured as the ratio between the longterm mean and standard deviation in total community cover $(S=\mu / \sigma)$, was significantly higher at northern sites (Fig. 4a,
Table 1). Accordingly, the analysis of regional residuals of the broad-scale dataset (1998-2005) indicated that warm sites showed lower variance components of total community cover than colder 


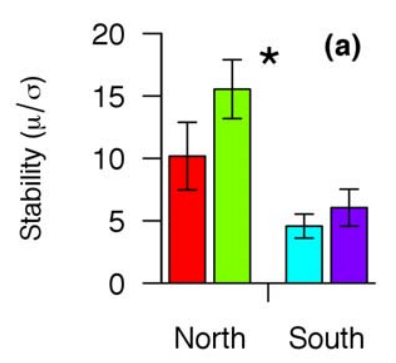

- Panul

口 Guanaqueros

口 Limarí

- Punta Talca
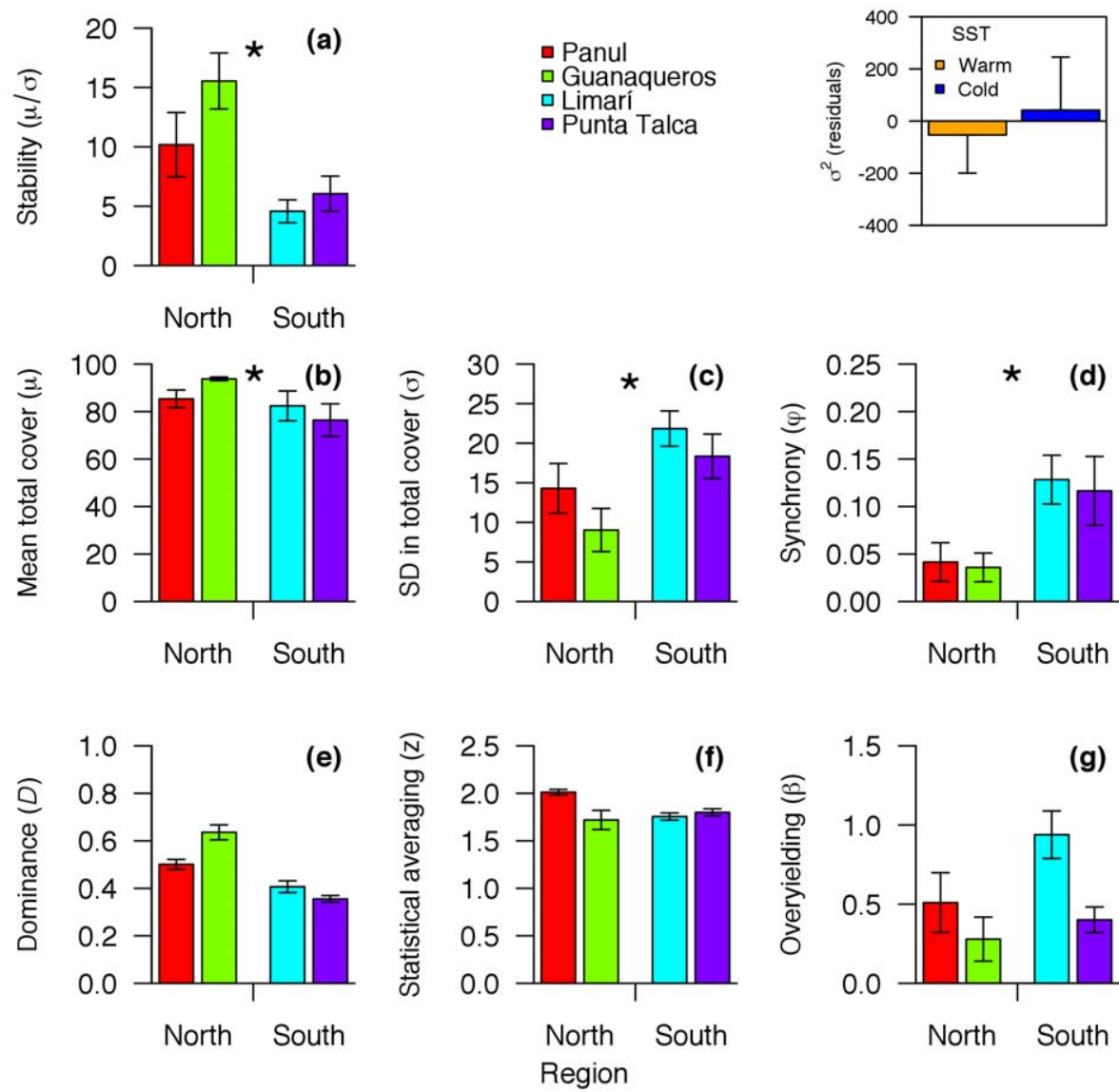

Figure 4. Temporal stability in sites located north (Panul and Guanaqueros) and south (Limari and Punta Talca) to the upwelling centre at Punta Lengua de Vaca (PLV). (a) Stability measured as (b) long-term mean in total community cover divided by its (c) standard deviation. (d) Synchrony in species' fluctuations. (e) Simpson's index of dominance. (f) Statistical averaging of species' fluctuations, expressed as the slope of the $\log _{10}$ transformation of Taylor's power law. (g) Overyielding, measured as the slope of the regression between taxon richness and longterm mean in total community cover. (Insert) Temporal variance components of total community cover estimated by REML from 17 sites between $29.47^{\circ} \mathrm{S}$ and $36.07^{\circ} \mathrm{S}$ (see Table S1), after removing the regional trend in the data by means of LOWESS regression. Values are expressed as means \pm SEM.

doi:10.1371/journal.pone.0054159.g004

sites (insert in Fig. 4; mean residual variance components $=-53.24$ and 42.01 for warm and cold SST, respectively). These differences were however statistically insignificant $\left(F_{1}\right.$, $\left.{ }_{15}=0.138, P=0.715\right)$.

The long-term mean of total community cover $(\mu)$ was significantly larger north than south of PLV (Fig. 4b; Table 1). In addition, the long-term standard deviation in total community cover $(\sigma)$ was significantly smaller at northern than southern sites (Fig. 4c, Table 1). Species synchrony was significantly lower north than south of PLV (Fig. 4d). Species dominance, statistical averaging, and overyielding did not vary statistically across the region (Figs. 4e, 4f, and 4g; Table 1).

Despite species dominance remained constant around PLV, the stabilising effects of dominant species probably differed between northern and southern sites. Significant negative relationships between Taylor's power law residuals and relative abundances were observed only in Panul and Guanaqueros, both sites experiencing warm SST (Fig. 5, permutation correlation tests). Therefore, dominant species were more stable than subordinate species in sites north, but not south of, Punta Lengua de Vaca.

\section{Discussion}

The mesoscale patterns here documented suggest that variation in environmental conditions over relatively small spatial scales can lead to significant differences in community-wide stability. We found that higher variability in sea surface temperature (SST) was related to higher stability and lower species synchrony (thus strengthened compensatory dynamics), but it was unrelated to other stabilising mechanisms such as statistical averaging and overyielding. Dominant species were significantly more stable than subordinate ones only in sites exposed to high SST variability, suggesting that particularly stable dominants may also have influenced community stability. Our findings agree with theoretical and empirical evidence for a positive effect of environmental fluctuations on compensatory dynamics. We suggest that ecological mechanisms evoking differential species' responses to environmental fluctuations (e.g. storage effect $[64,65]$ ) play a relevant role in generating compensatory dynamics and maintaining a constant provision of ecosystem properties under fluctuating environmental conditions.

Our analysis of SST showed that temperature records were warmer and more variable at sites north than south PLV, which experience reduced and intense upwelling activity, respectively. 
Table 1. Results of nested ANOVA of the effects of Region (north and south of Punta Lengua de Vaca, fixed factor) and Site (Panul, Guanaqueros, Limarí, or Punta Talca; random factor and nested within Region) on stability, species synchrony, species dominance, statistical averaging, and overyielding.

\begin{tabular}{|c|c|c|c|c|c|c|c|c|c|}
\hline \multirow[b]{2}{*}{ Source of variation } & \multicolumn{3}{|c|}{ Region (1) } & \multicolumn{3}{|c|}{ Site(Region) (2) } & \multirow{2}{*}{$\begin{array}{l}\text { Residual (36) } \\
\text { MS }\end{array}$} & \multirow{2}{*}{$\begin{array}{l}\text { Pooled residual (38) } \\
\text { MS }\end{array}$} & \multirow[b]{2}{*}{ MS denominator } \\
\hline & MS & $\mathbf{F}$ & & MS & $\mathbf{F}$ & & & & \\
\hline \multicolumn{10}{|l|}{ Response variable } \\
\hline Stability & 0.78 & 19.03 & $* * *$ & 0.06 & 1.42 & & 0.040 & 0.041 & Pooled \\
\hline Mean total cover & 2284.63 & 8.27 & $* *$ & 166.40 & 0.59 & & 282.455 & 276.347 & Pooled \\
\hline Std. dev. total cover & 1009.08 & 13.03 & $* *$ & 144.22 & 1.96 & & 73.733 & 77.442 & Pooled \\
\hline Species synchrony & 3.54 & 21.82 & $* * *$ & 0.19 & 1.16 & & 0.161 & 0.162 & Pooled \\
\hline Dominance & 0.43 & 8.73 & & 0.05 & 8.32 & $* *$ & 0.006 & & Site(Region) \\
\hline Statistical averaging & 0.12 & 0.53 & & 0.22 & 6.56 & $* *$ & 0.034 & & Site(Region) \\
\hline Overyielding & 0.76 & 0.89 & & 0.85 & 4.10 & $* *$ & 19.930 & 19.056 & Pooled \\
\hline
\end{tabular}

Despite the small differences in SST regimes detected, these confirm the difference in mesoscale oceanographic conditions across PLV. Our results are in good agreement with previous work showing significant differences between north and south PLV in terms of SST, $\mathrm{CO}_{2}$ saturation, and the magnitude and variability of wind speed $[22,32,66]$, which can be associated with temporal fluctuations in primary productivity [36]. Accordingly, the spatiotemporal variation in SST is well correlated with that in biological oceanographic features and supports our interpretation of SST patterns as a proxy for local environmental conditions.

Following the stability metric we chose $(S=\mu / \sigma$, [13]), higher values at sites experiencing warmer and variable SST indicated increased mean $(\mu)$ and decreased standard deviation $(\sigma)$ of total community cover. The marginal difference in $\mu$ between upwelling regimes suggests that decreased temporal variability at sites affected by low upwelling intensity was more important. Species dominance, statistical averaging, and overyielding did not vary between environmental regimes, indicating that reduced synchronisation in species abundances can be associated to lower temporal variability [5] at sites experiencing high temporal variation in SST.

The differences in terms of stability and compensatory dynamics between environmental regimes can be explained in the light of differential amounts of temporal variability, assuming that climate and broad-scale processes strongly influence population synchrony $[18,67]$. Separation of the temporal component of species' niches promotes coexistence and compensatory dynamics [20]. Temporal changes in environmental factors like temperature stimulate compensatory dynamics thanks to differences in temporal resource use patterns between species [68,69]. Long-term manipulative experiments suggest that environmental variation allows the expression of niche differences between competing species, which results in a positive effect of diversity on stability through niche partitioning [70,71]. On the other hand, weakening of the diversity-stability relationship toward higher latitudes can be a response to the stronger influence of environmental factors on species richness and composition [72]. Thus, exogenous factors, such as environmental fluctuations, seem to have strong and determinant effects on the main mechanisms driving community stability.
The effects of dominant species did vary between warm and cold sites. Only in the northern sites, residuals from Taylor's power law estimated from dominant species were significantly lower than those estimated from subordinate species. This indicates that dominant species were less variable over time in sites exposed to warm and variable SST, and that such dominant species may have influenced the community-wide stability north Punta Lengua de Vaca. These communities were dominated by chthamalid barnacles, which have a complex life cycles with a planktonic stage that might last for several weeks, allowing barnacles to rapidly colonise disturbance-generated patches of empty substratum [73]. It might be hypothesised that increased supply of barnacle larvae to our low-upwelling study sites [29] might have conferred stability to the whole community by recolonising patches of bare rock generated by disturbances or predation (e.g. by the sea sun Heliaster helianthus; [74]). From a metacommunity perspective, the mass effect of immigration from source populations can be seen as a mechanism that buffers population abundances when environmental conditions are unfavourable for a given species [75]. In addition to differential environmental responses, mass effects are pivotal for stability at the ecosystem-level [16]. Accordingly, the storage effect model [64] seems to fit to our observational data, given the dominance of long-distance dispersing species in sites with stronger compensatory dynamics.

Following the negative relation between recruitment of chthamalid barnacles and upwelling intensity [30,76], barnacles were sparse south PLV and the assemblages were dominated by red algae, which usually experience strong dispersal limitation [77]. Therefore, it can be suggested that local mechanisms are relevant in driving the structure and stability of these communities. One type of these local processes might correspond to facilitative effects on other species. For example, Mazzaella laminarioides' leathery morphology can generate understorey environmental conditions different from the overall environment, and thus positive covariance among obligate understorey species as seen in other temperate shores [5,78,79]. In central Chile, the abundance of crustose algae like Lithothamnion spp. are positively correlated with that of corticated algae [38], suggesting that crustose species, which are specialised to shaded conditions [80], 




Figure 5. Correlation between species relative abundances (\%-covers) and residuals from Taylor's power law. (a, b) Sites located north and $(c, d)$ south to the upwelling centre at Punta Lengua de Vaca (PLV). Larger negative residuals indicate more stable abundances. doi:10.1371/journal.pone.0054159.g005

can colonise more stressful habitats thanks to habitat amelioration by the dominant $M$. laminarioides. These positive relationships might have contributed with synchronous species dynamics and thus with lower stability in both sites south PLV. Upwelling intensity, however, can dampen positive interactions, probably due to enhanced nutrient concentrations. Manipulative evidence shows that the turf-forming alga Gelidium chilense has stronger facilitative effects on recruitment of $P$. purpuratus on areas downstream of upwelling sites [26]. The role of morphological traits of habitatforming species should be comparatively analysed in order to assess the effect of positive interactions on species synchrony across differential environmental settings.

Here, we have presented multiyear observational evidence for a relationship between environmental fluctuations and community stability. We have observed contrasting structural configurations in low- vs. high-upwelling sites, defined by life histories that respond to different scales of environmental variation: life-histories that respond to broad-scale processes (i.e. dispersal) dominated lowupwelling sites, while life-histories that respond to fine-scale environmental variation dominated high-upwelling sites. Our results indicate that higher environmental variability might lead to stronger compensatory dynamics and thus to higher community-wide stability. Such a relationship has been largely proposed by theoretical models and laboratory-based experiments, but rarely by field observations that integrate natural filters and broader environmental conditions. Still is necessary to test for differences in environmental tolerances between sites experiencing different levels of environmental fluctuations; manipulative experiments seem ideal to test if this assumption holds at the mesoscale. Our results support the idea that exogenously driven compensatory dynamics, in addition to stabilising effects of dominant species, can determine the stability of ecosystems facing environmental fluctuations.

\section{Supporting Information}

Table S1 Summary of sampling sites used to estimate variance components (REML) of total community cover. Species percentage covers were estimated seasonally in each site from 1998 to 2005 (Sampling year). *Sites were categorised as experiencing warm or cold sea surface temperatures (SST), according to satellite imaging and in situ records [1-3].

(DOC) 


\section{Acknowledgments}

We thank M. A. Aguilera, J. Gajardo, O. Cerda, I. P. Moreno, K. Jeno, and the Changolab working group for field support and discussions that improved early versions of this manuscript. S. A. Navarrete shared historical data of species abundances.

\section{References}

1. Hooper DU, Adair EC, Cardinale BJ, Byrnes JEK, Hungate BA, et al. (2012) A global synthesis reveals biodiversity loss as a major driver of ecosystem change. Nature 486: 105-108.

2. Barnosky AD, Hadly EA, Bascompte J, Berlow EL, Brown JH, et al. (2012) Approaching a state shift in Earth's biosphere. Nature 486: 52-58.

3. Cardinale BJ, Duffy JE, Gonzalez A, Hooper DU, Perrings G, et al. (2012) Biodiversity loss and its impact on humanity. Nature 486: 59-67.

4. Doak DF, Bigger D, Harding EK, Marvier MA, O'Malley RE, et al. (1998) The statistical inevitability of stability-diversity relationships in community ecology. Am Nat 151: 264-276.

5. Bulleri F, Benedetti-Cecchi L, Cusson M, Maggi E, Arenas F, et al. (2012) Temporal stability of European rocky shore assemblages: variation across a latitudinal gradient and the role of habitat-formers. Oikos 121: 1801-1809.

6. Gonzalez A, Loreau M (2009) The causes and consequences of compensatory dynamics in ecological communities. Annu Rev Ecol Evol S 40: 393-414.

7. Grman E, Lau JA, Schoolmaster DR, Gross KL (2010) Mechanisms contributing to stability in ecosystem function depend on the environmental context. Ecol Lett 13: 1400-1410.

8. Polley HW, Wilsey BJ, Derner JD (2007) Dominant species constrain effects of species diversity on temporal variability in biomass production of tallgrass prairie. Oikos 116: 2044-2052.

9. Huston MA (1997) Hidden treatments in ecological experiments: re-evaluating the ecosystem function of biodiversity. Oecologia 110: 449-460.

10. Thibaut LM, Connolly SR (2012) Understanding diversity-stability relationships: towards a unified model of portfolio effects. Ecol Lett: n/a-n/a.

11. Taylor LR (1961) Aggregation, variance and the mean. Nature 189: 732-735.

12. Tilman D (1999) The ecological consequences of changes in biodiversity: a search for general principles. Ecology 80: 1455-1474.

13. Lehman CL, Tilman D (2000) Biodiversity, stability, and productivity in competitive communities. Am Nat 156: 534-552.

14. Kilpatrick AM, Ives AR (2003) Species interactions can explain Taylor's power law for ecological time series. Nature 422: 65-68.

15. Ives AR, Gross K, Klug JL (1999) Stability and variability in competitive communities. Science 286: 542-544.

16. Loreau M, Mouquet N, Gonzalez A (2003) Biodiversity as spatial insurance in heterogeneous landscapes. P Natl Acad Sci USA 100: 12765-12770.

17. Pandit S, Kolasa J, Cottenie K (2012) Population synchrony decreases with richness and increases with environmental fluctuations in an experimental metacommunity. Oecologia: 1-11.

18. Houlahan JE, Currie DJ, Cottenie K, Cumming GS, Ernest SKM, et al. (2007) Compensatory dynamics are rare in natural ecological communities. P Natl Acad Sci USA 104: 3273-3277.

19. Downing AL, Brown BL, Perrin EM, Keitt TH, Leibold MA (2008) Environmental fluctuations induce scale-dependent compensation and increase stability in plankton ecosystems. Ecology 89: 3204-3214.

20. Chesson P, Pacala S, Neuhauser C (2001) Environmental niches and ecosystem functioning. In: Kinzig A, Pacala S, Tilman D, editors. The Functional Consequences of Biodiversity: Princeton University Press.

21. Norberg J, Swaney DP, DushoffJ, Lin J, Casagrandi R, et al. (2001) Phenotypic diversity and ecosystem functioning in changing environments: A theoretical framework. Proceedings of the National Academy of Sciences 98: 11376-11381.

22. Garreaud RD, Muñoz RC (2005) The low-level jet off the west coast of subtropical South America: Structure and variability. Monthly Weather Review 133: 2246-2261

23. Strub PT, Mesías J, Montecinos V, Rutland J, Salinas S (1998) Coastal ocean circulation off western South America. In: Robinson AR, Brink KH, editors. The Sea: John Wiley \& Sons, Inc.

24. Wieters EA, Broitman BR, Branch GM (2009) Benthic community structure and spatiotemporal thermal regimes in two upwelling ecosystems: Comparisons between South Africa and Chile. Limnol Oceanogr 54: 1060-1072.

25. Broitman BR, Szathmary PL, Mislan KAS, Blanchette CA, Helmuth B (2008) Predator-prey interactions under climate change: the importance of habitat vs body temperature. Oikos 118: 219-224.

26. Wieters EA (2005) Upwelling control of positive interactions over mesoscales: a new link between bottom-up and top-down processes on rocky shores. Mar Ecol Prog Ser 301: 43-54.

27. Nielsen KJ, Navarrete SA (2004) Mesoscale regulation comes from the bottomup: intertidal interactions between consumers and upwelling. Ecol Lett 7: 31-41.

28. Menge BA (2000) Top-down and bottom-up community regulation in marine rocky intertidal habitats. J Exp Mar Biol Ecol 250: 257-289.

29. Navarrete SA, Wieters EA, Broitman BR, Castilla JC (2005) Scales of benthicpelagic coupling and the intensity of species interactions: from recruitment limitation to top-down control. P Natl Acad Sci USA 102: 18046-18051.

\section{Author Contributions}

Conceived and designed the experiments: NV BB. Performed the experiments: NV AEG TM. Analyzed the data: NV AEG TM BB. Contributed reagents/materials/analysis tools: AEG BB. Wrote the paper: NV BB.

30. Blanchette CA, Broitman BR, Gaines SD (2006) Intertidal community structure and oceanographic patterns around Santa Cruz Island, California, USA. Mar Biol 149: 689-701.

31. Hormazabal S, Shaffer G, Leth O (2004) Coastal transition zone off Chile. J Geophys Res C 109: C01021.

32. Garreaud RD, Rutllant JA, Muñoz RC, Rahn DA, Ramos M, et al. (2011) VOCALS-CUpEx: the Chilean Upwelling Experiment. Atmos Chem Phys 11: 2015-2029.

33. Muñoz RC (2008) Diurnal cycle of surface winds over the subtropical southeast Pacific. J Geophys Res-Atmos 113: D13107.

34. Rahn DA, Garreaud RD, Rutllant JA (2011) The Low-Level Atmospheric Circulation near Tongoy-Bay Point Lengua de Vaca (Chilean Coast, 30 degrees S). Monthly Weather Review 139: 3628-3647.

35. Vargas CA, Narvaez DA, Pinones A, Navarrete SA, Lagos NA (2006) River plume dynamic influences transport of barnacle larvae in the inner shelf off central Chile. J Mar Biol Assoc UK 86: 1057-1065.

36. Rutllant J, Montecino V (2002) Multiscale upwelling forcing cycles and biological response off north-central Chile. Rev Chil Hist Nat 75: 217-231.

37. Broitman BR, Véliz F, Manzur T, Wieters EA, Finke GR, et al. (2011) Geographic variation in diversity of wave exposed rocky intertidal communities along central Chile. Rev Chil Hist Nat 84: 143-154.

38. Broitman BR, Navarrete SA, Smith F, Gaines SD (2001) Geographic variation of southeastern Pacific intertidal communities. Mar Ecol Prog Ser 224: 21-34.

39. Rivadeneira MM, Fernandez M, Navarrete SA (2002) Latitudinal trends of species diversity in rocky intertidal herbivore assemblages: spatial scale and the relationship between local and regional species richness. Mar Ecol Prog Ser 245: 123-131.

40. Santelices B (1990) Patterns of organizations of intertidal and shallow subtidal vegetation in wave exposed habitats of central Chile. Hydrobiologia 192: 35-57.

41. Valdivia N, Molis M (2009) Observational evidence of a negative biodiversitystability relationship in intertidal epibenthic communities. Aquat Biol 4: 263271.

42. Connolly SR, Muko S (2003) Space preemption, size-dependent competition, and the coexistence of clonal growth forms. Ecology 84: 2979-2298.

43. Dethier MN, Graham ES, Cohen S, Tear LM (1993) Visual versus randompoint percent cover estimations: 'objective' is not always better. Mar Ecol Prog Ser 96: $93-100$

44. Cavanaugh KC, Siegel DA, Kinlan BP, Reed DC (2010) Scaling giant kelp field measurements to regional scales using satellite observations. Mar Ecol Prog Ser 403: 13-27.

45. Valdivia N, Gollety C, Migne A, Davoult D, Molis M (2012) Stressed but stable: Canopy loss decreased species synchrony and metabolic variability in an intertidal hard-bottom community. PLoS ONE 7: e36541.

46. Espoz C, Lindberg DR, Castilla JC, Simison WB (2004) Los Patelogastropodos intermareales de Chile y Perú. Rev Chil Hist Nat 77: 257-283.

47. Hoffmann AJ, Santelices B (1997) Flora marina de Chile central. Santiago: Ediciones Universidad Católica de Chile. 434 p.

48. Oliva D, Castilla JC (1992) Guía para el reconocimiento y morfometría de diez especies del género Fissurella Brugiere, 1789 (Mollusca : Gastropoda) comunes en la pesquería y conchales indígenas de Chile central y sur. Gayana Zool 56: 77108.

49. Chapman MG (2002) Early colonization of shallow subtidal boulders in two habitats. J Exp Mar Biol Ecol 275: 95-116.

50. Smale DA (2010) Monitoring marine macroalgae: the influence of spatial scale on the usefulness of biodiversity surrogates. Divers Distrib 16: 985-995.

51. Tapia FJ, Navarrete SA, Castillo M, Menge BA, Castilla JC, et al. (2009) Thermal indices of upwelling effects on inner-shelf habitats. Prog Oceanogr 83: 278-287.

52. Anderson MJ, Willis TJ (2003) Canonical analysis of principal coordinates: a useful method of constrained ordination for ecology. Ecology 84: 511-525.

53. Anderson MJ, Ellingsen KE, McArdle BH (2006) Multivariate dispersion as a measure of beta diversity. Ecol Lett 9: 683-693.

54. Holling CS (1973) Resilience and stability of ecological systems. Annu Rev Ecol Syst 4: 1-23.

55. Pimm SL (1991) The balance of nature?: ecological issues in the conservation of species and communities. Chicago: The University of Chicago Press.

56. Cottingham KL, Brown BL, Lennon JT (2001) Biodiversity may regulate the temporal variability of ecological systems. Ecol Lett 4: 72-85.

57. Hooper DU, Chapin FS, Ewel JJ, Hector A, Inchausti P, et al. (2005) Effects of biodiversity on ecosystem functioning: a consensus of current knowledge. Ecol Monogr 75: 3-35.

58. MacArthur RH (1955) Fluctuations of animal populations and a measure of community stability. Ecology 36: 533-536. 
59. Elton SC (1958) The ecology of invasions by animals and plants. Chicago, USA: The University of Chicago Press. $181 \mathrm{p}$.

60. Loreau M, de Mazancourt C (2008) Species synchrony and its drivers: neutral and nonneutral community dynamics in fluctuating environments. Am Nat 172: E48-E66.

61. Box GEP, Hunter WG, Hunter JS (1978) Statistics for experimenters: an introduction to design, data analysis, and model building: John Wiley and Sons. $672 \mathrm{p}$.

62. Quinn GP, Keough MJ (2002) Experimental design and data analysis for biologists. Cambridge: Cambridge University Press. 537 p.

63. R Development Core Team (2012) R: a language and environment for statistical computing. 2.15.0 ed. Vienna: R Foundation for Statistical Computing.

64. Chesson P (1994) Multispecies competition in variable environments. Theor Popul Biol 45: 227-276.

65. Chesson P (2000) Mechanisms of maintenance of species diversity. Annu Rev Ecol Syst 31: 343-366.

66. Torres R, Ampuero P (2009) Strong CO(2) outgassing from high nutrient low chlorophyll coastal waters off central Chile (30 degrees S): The role of dissolved iron. Estuar Coast Shelf Sci 83: 126-132.

67. Valone TJ, Barber NA (2008) An empirical evaluation of the insurance hypothesis in diversity-stability models. Ecology 89 : 522-531.

68. Chesson PL, Warner RR (1981) Environmental variability promotes coexistence in lottery competitive systems. Am Nat 117: 923-943.

69. Hutchinson GE (1961) The paradox of the plankton. The American Naturalist 95: 137-145.
70. Stachowicz JJ, Graham M, Bracken MES, Szoboszlai AI (2008) Diversity enhances cover and stability of seaweed assemblages: the role of heterogeneity and time. Ecology 89: 3008-3019.

71. Cardinale BJ, Wrigh JP, Cadotte MW, Carroll IT, Hector A, et al. (2007) Impacts of plant diversity on biomass production increase through time because of species complementarity. P Natl Acad Sci USA 104: 18123-18128.

72. Campbell V, Murphy G, Romanuk TN (2011) Experimental design and the outcome and interpretation of diversity-stability relations. Oikos 120: 399-408.

73. Nybakken JW, Bertness DM (2005) Marine Biology: an ecological approach. San Francisco: Benjamin Cummings.

74. Navarrete SA, Manzur T (2008) Individual- and population-level responses of a keystone predator to geographic variation in prey. Ecology 89: 2005-2018.

75. Leibold MA, Holyoak M, Mouquet N, Amarasekare P, Chase JM, et al. (2004) The metacommunity concept: a framework for multi-scale community ecology. Ecol Lett 7: 601-613.

76. Lagos NA, Castilla JC, Broitman BR (2008) Spatial environmental correlates of benthic recruitment: a test using intertidal barnacles along the coast of northern Chile. Ecol Monogr 78: 245-261.

77. Kinlan BP, Gaines SD (2003) Propagule dispersal in marine and terrestrial environments: A community perspective. Ecology 84: 2007-2020.

78. Bertness D, Leonard G, Levine J, Schmidt P, Ingraham A (1999) Testing the relative contribution of positive and negative interactions in rocky intertidal communities. Ecology 80: 2711-2726.

79. Menge BA (1978) Predation intensity in a rocky intertidal community. Oecologia 34: $17-35$.

80. Steneck R (1986) The ecology of coralline algal crusts: convergent patterns and adaptative strategies. Annu Rev Ecol Syst 17: 273-303. 